\title{
Metastatic Implantation of Esophageal Cancer at PEG Tube Site: Case Report and Review of Literature
}

\author{
Jenny Joseph ${ }^{1}$, Judith Aaron ${ }^{1 *}$, Johny K Joseph ${ }^{1}$, Jose Tom ${ }^{1}$, Bindu TG ${ }^{2}$, Anuradha $\mathbf{R}^{3}$ and Jino Thomas ${ }^{4}$ \\ ${ }^{1}$ Department of Radiation Oncology, Caritas Cancer Institute, Thellakom, Kerala, India \\ ${ }^{2}$ Department of Pathology, Caritas Hospital, Thellakom, Kerala, India \\ ${ }^{3}$ Department of Radiodiagnosis, Caritas Hospital, Thellakom, Kerala, India \\ ${ }^{4}$ Department of Gastroenterology, Caritas Hospital, Thellakom, Kerala, India
}

*Corresponding author: Judith Aaron, Department of Radiation Oncology, Caritas Cancer Institute, Thellakom, Kerala, India, E-mail: judithaaron3@gmail.com Received date: October 11, 2018; Accepted date: October 30, 2018; Published date: November 06, 2018

Copyright: $\odot 2018$ Joseph J, et al. This is an open-access article distributed under the terms of the Creative Commons Attribution License, which permits unrestricted use, distribution, and reproduction in any medium, provided the original author and source are credited.

\begin{abstract}
Percutaneous Endoscopic Gastrostomy (PEG) is a common procedure done in patients with Carcinoma Esophagus whose nutritional status is compromised due to the primary disease and treatment related side effects. A rare and serious complication of this procedure is the metastatic spread of tumour from the esophagus to the gastrostomy site. We discuss a case of 70-year-old lady with Stage IVA (T4bNOM0) Squamous cell carcinoma esophagus who underwent PEG insertion prior to radical radiation treatment. 9 months later, she presented with a painful, ulceroproliferative growth at stomal site. It was histopathologically proven to be a metastasis from the primary. Palliative radiation with a dose of $30 \mathrm{~Gy}$ in 10 fractions by 3D conformal technique was delivered and good clinical response was achieved. However preventive methods such as surgical gastrostomy tube insertion procedures and delaying the timing of insertion of PEG tube to after commencing definitive treatment might help to decrease the risk. Positron Emission Tomography-Computed Tomography (PET/CT) scan is an effective tool for early detection of PEG site metastasis.
\end{abstract}

Keywords: PEG site metastasis; Carcinoma esophagus; Tumour implantation

\section{Introduction}

Nutritional support is of prime importance in carcinoma esophagus and percutaneous endoscopic gastrostomy (PEG) placement is a recommended option for successful completion of definitive treatment. However, it is associated with a small risk of developing metastasis at the stomal site. We present such a case and discuss early detection, treatment options and possible preventive measures to avert this risk.

\section{Case Report}

A 70-year-old lady with no known comorbidities was diagnosed to have Stage IVA squamous cell carcinoma lower third esophagus in September 2017. She had no relevant family and psychosocial history. She was planned for radical radiation and prior to starting treatment, PEG placement was done by pull string technique to maintain nutritional status. She received a dose of $5400 \mathrm{cGy} / 30 \mathrm{~F}$ to lower third esophagus and draining lymph node stations with Intensity Modulated Radiotherapy technique (IMRT). First clinical assessment done at 6 weeks post radiation revealed symptomatic improvement. In February 2018 (3 months post radiation), Oesophago-gastroduodenoscopy (OGD) showed stricture with ulceration at $34 \mathrm{~cm}$, stomach showed PEG tube bumber in situ, otherwise unremarkable. Biopsy from the stricture was reported as squamous cell carcinoma, moderately differentiated. A whole body Positron Emission TomographyComputed Tomography (PET/CT) scan done revealed $18 \mathrm{~F}$ fluorodeoxyglucose (FDG) avid active residual primary lower esophagus extending upto the gastro-esophageal (GE) junction. There was also an abnormal increased FDG uptake with a maximum Standardized Uptake Value (SUV) of 8 at the PEG site on the anterior abdominal wall suggestive of inflammation (Figure 1).

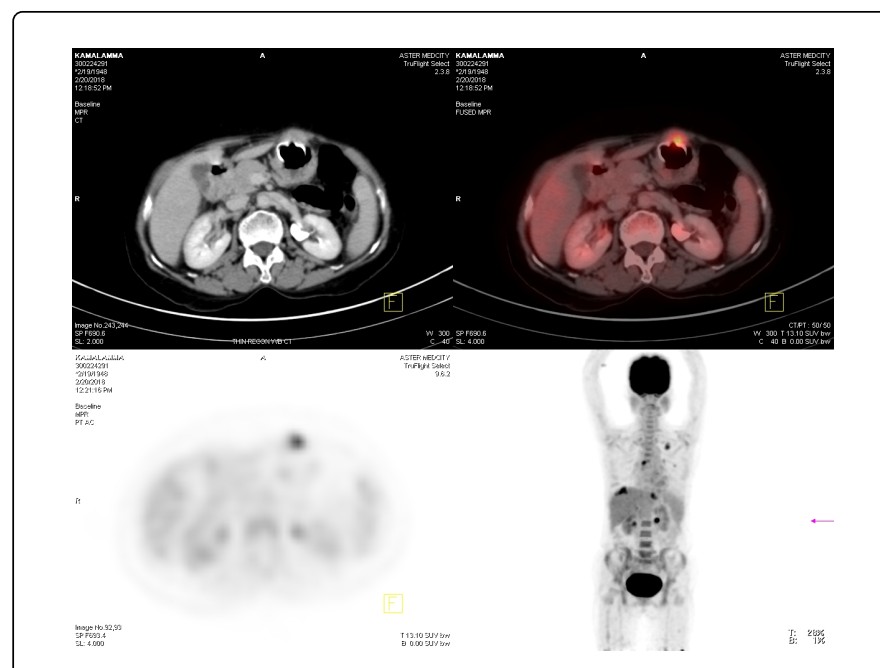

Figure 1: Whole body PET CT scan showing abnormal FDG uptake at PEG site suggestive of inflammation.

In view of advanced age and residual disease, she was offered palliative chemotherapy. Due to poor tolerance, chemotherapy was discontinued after 2 months. She underwent PEG removal in view of discomfort at the stomal site. 
In June 2018, she came with complaints of painful ulceroproliferative growth at PEG site with mild discharge. There was a friable ulcerative growth at gastrostomy site (Figure 2). A whole body $\mathrm{PET} / \mathrm{CT}$ scan showed a metabolically active residual primary in the lower esophagus extending to the GE junction, a $5.6 \times 2.9 \times 3.5 \mathrm{~cm}$ lesion with maximum SUV 29.5 at the anterior wall of stomach with soft tissue deposit in the anterior abdominal wall at the PEG site (Figure 3). Biopsy of the growth was reported as moderately differentiated squamous cell carcinoma identical to the primary histology (Figure 4). As she was symptomatic for the PEG site recurrence, palliative radiation therapy of $3000 \mathrm{cGy}$ in 10 fractions by $3 \mathrm{D}$ conformal technique was delivered to the local site. Clinical assessment one month after the palliative radiation showed complete resolution of the exophytic growth on the abdominal wall with complete relief of pain and discharge from the PEG site (Figure 5). CT imaging showed decrease in the size of soft tissue density lesion in the epigastriumto a size of $3.5 \times 2.6 \times 1.8 \mathrm{~cm}$. She is currently asymptomatic and on regular follow up.



Figure 2: Metastatic implantation at PEG site $2 \times 2.5 \mathrm{~cm}$ friable ulceroproliferative growth.

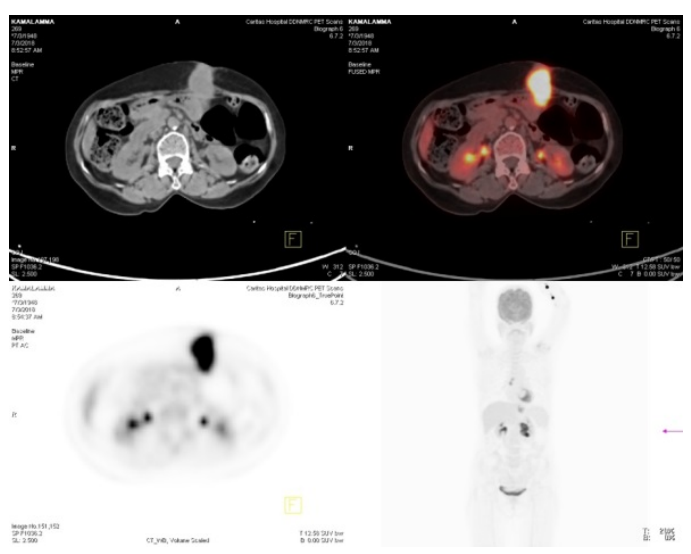

Figure 3: Whole body PET CT scan showing metabolically active disease at the anterior wall of stomach and soft tissue deposit in the anterior abdominal wall at the PEG site.

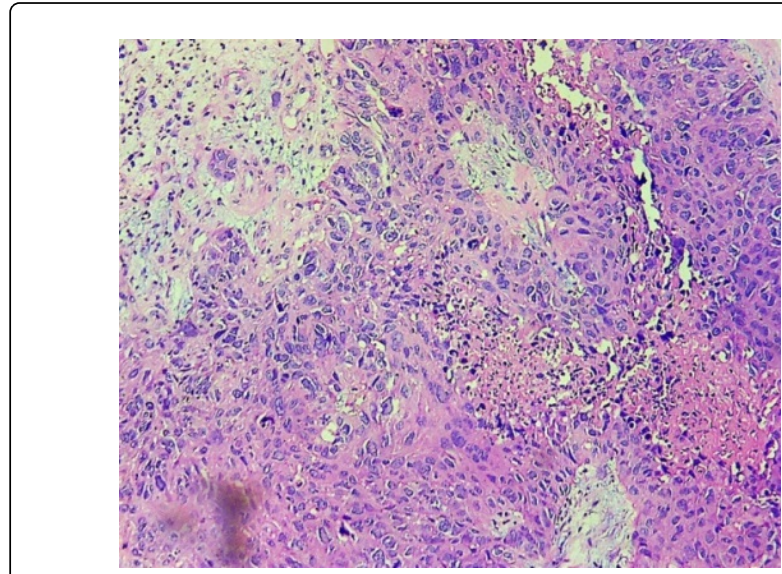

Figure 4: Showing infiltrating squamous cell carcinoma identical to the primary histology (20X H\&E stain)

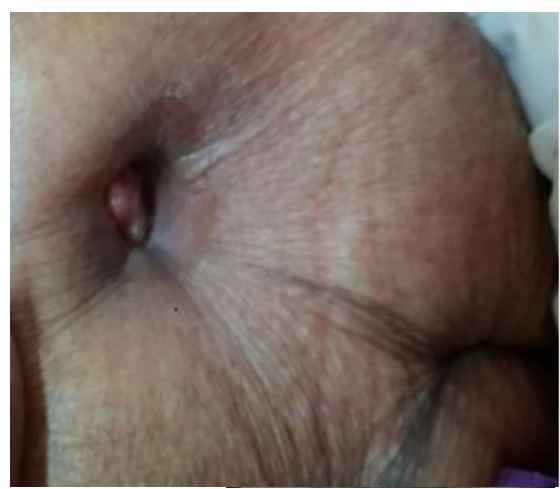

Figure 5: Resolving phase of the exophytic growth after palliative radiation.

\section{Discussion}

This case shares our institution's first experience with carcinoma esophagus metastasizing to the gastrostomy site. Though PEG is a universally accepted means of enteral feeding, stomal metastasis from primary cancer is an alarming concern [1]. PEG site must be evaluated at regular intervals with careful attention to the patient's complaints and unusual skin changes at the stomal site. When needed, a biopsy must be done to distinguish a tumour from an exophytic granulation tissue. PET-CT imaging might help to detect an early asymptomatic stomal metastasis [2]. Synchronous distant metastasis and coexisting disease at the primary site can also be assessed. De Monès et al. [3] pointed out that even a hypermetabolic uptake seen in PET-CT images near or around the gastrostomy site must be carefully monitored for metastasis. Retrospectively analyzing, the increased uptake noted in the initial PET/CT scan of our patient must have been an indication of early recurrence which was considered as inflammatory change.

The prognosis and outcome of this rare occurrence is poor. A study by Fonseca et al. [4] showed a good two year survival following bloc resection of PEG site recurrence including a total gastrectomy. Even subtotal gastrectomy with removal of a part of abdominal wall has also 
Citation: Joseph J, Aaron j, Joseph JK, Tom J, Bindu TG, et al. (2018) Metastatic Implantation of Esophageal Cancer at PEG Tube Site: Case

been tried in earlier cases. Though surgical resection has shown good curative result, it can only be considered when there is complete regression of the primary with no evidence of metastasis elsewhere Palliative radiation to the PEG site metastasis can be an effective tool in patients with residual primary lesion as in our patient.

Risk factors studied by Cappel et al. [5] were poorly or moderately differentiated squamous cell carcinoma histology, advanced stage at presentation, pullstring technique of PEG placement, untreated primary cancer before insertionand time more than and equal to 3 months after insertion. This case had all the above factors. To prevent direct implantation, contact of gastrostomy tube with the tumour must be avoided by using a sheath or overtube. Though prophylactic PEG (insertion before definitive treatment) decreases malnourishment and weight loss, it is not favoured, as the risk of tumor seeding seems to be higher in cases with active tumor load [6]. Deferring PEG insertion till the initiation of radiation or chemotherapy therefore will help to decrease this risk. Despite this potential risk, we should not defer PEG placement in nutritionally compromised cancer patients but instead explain and discuss this risk with the patient and relatives in their treatment consent.

\section{Conflicts of Interest}

None.

\section{References}

1. Sousa AL, Sousa D, Velasco F, Açucena F, Lopes A (2013) Rare complication of percutaneous endoscopic gastrostomy: Ostomy metastasis of esophageal carcinoma. World J Gastrointest Oncol 5: 204-206.

2. Purandare NC, Rangarajan V, Sharma AR, Shah S, Singh N (2008) Percutaneous endoscopic gastrostomy site metastases in head and neck cancer: Use of FDG PET-CT. Diagn Interv Radiol 14: 88-93.

3. De Monès E, Castetbon V, Digue L, Baltazart B, Fernandez P (2014) Diagnosis of squamous cell carcinoma metastasis with 18F-FDG PET/CT in stoma after percutaneous endoscopic gastrostomy: A rare and poorly known iatrogenic cause of spread of head and neck cancer. Clin Nucl Med 39: 544-546.

4. Fonseca J, Adriana C, Fróis-Borges M, Meira T, Oliveira G (2015) Ostomy metastasis after pull endoscopic gastrostomy: A unique favorable outcome. Nutr Hosp 31: 1879-1881.

5. Cappell M (2007) Risk factors and risk reduction of malignant seeding of the percutaneous endoscopic gastrostomy track from pharyngoesophageal malignancy: A review of all 44 known reported cases. Am J Gastroenterol 102: 1307-1311.

6. Silander E, Nyman J, Bove M, Johansson L, Larsson S (2012) Impact of prophylactic percutaneous endoscopic gastrostomy on malnutrition and quality of life in patients with head and neck cancer: A randomized study. Head Neck 34: 1-9. 